\title{
Comparison of Medical Education and Requirements for Training in the Interventional Neuroradiology in China, Japan and Korea
}

\author{
Lin Bo Zhao, MD², Shigeru Miyachi, MD², Hai Bin Shi, MD², Dae Chul Suh, MD
}

The interventional neuroradiology (INR, or neurointerventional surgery) became a rapidly emerging specialty since the first Working group in Interventional Neuroradiology (WIN) meeting was held in Santa Barbara in 1980 by 15 pioneers. Although the specialty has been led by neuroradiologists, other specialists of neurosurgery and neurology have become involved. Due to diverse background of the specialties with inadequate requirement of education and training, proper level of training standard and quality assurance may be achieved for outcomes of treated patients with neurovascular diseases. In East Asia, there are less inter-relationship of education and training among China, Japan and Korea when compared to the learning opportunities in western countries from the three nations. Therefore, we present the current status and difference of medical education system and compare INR training to improve understanding of INR development in the adjacent countries.

Key Words : Medical Education; Interventional neuroradiology; Training

Recent development of interventional neuroradiology (INR) has contributed to its important role in the treatment of intracranial and spinal vascular diseases, such as intracranial aneurysms, acute ischemic stroke,

'Department of Radiology and Research Institute of Radiology, University of Ulsan, College of Medicine, Asan Medical Center, Korea

2Department of Radiology, First Affiliated Hospital of Nanjing Medical University, First Affiliated Hospital of Nanjing Medical University, China

${ }^{3}$ Department of Neurosurgery, Nagoya University Graduate School of Medicine, Japan

Received February 3, 2013; accepted after revision February 19, 2013.

Correspondence to: Dae Chul Suh, MD, Department of Radiology, University of Ulsan, College of Medicine, Asan Medical Center, 88, Olympic-ro 43-gil, Songpa-gu, Seoul 138-736, Korea.

Tel. 82.2.3010.4366 Fax. 82.2.476.0090

E-mail: dcsuh@amc.seoul.kr

This is an Open Access article distributed under the terms of the Creative Commons Attribution Non-Commercial License (http://creativecommons.org/licenses/by-nc/3.0) which permits unrestricted non-commercial use, distribution, and reproduction in any medium, provided the original work is properly cited. traumatic or dural arteriovenous fistulas and arteriovenous malformations, or in the presurgical embolization of cranial and spinal hypervascular tumors, and in the devascularization of patients with epistaxis or acute bleeding.

With the growth of INR activities, neurointerventionists have rapidly emerged from different specialties. Although the creation and development of INR were initiated by neuroradiologists, other medical specialists have become progressively more involved in the procedure and management, particularly neurosurgeons and, to a lesser extent, neurologists [1]. It is imperative that adequate training and quality assurance be in place to ensure that the use of neurointerventional procedures impact favorably upon outcomes of patients with cerebrovascular diseases. To maintain and to improve the general quality level of its specialty, the first rules concerning the training in Interventional Neuroradiology (INR) was published in 1998 [2], few years after the foundation of the World Federation of Interventional and Therapeutic Neuroradiology (WFITN). Many medical 
associations have published their own charters or requirements for INR, such as European Union of Medical Specialists Division of Neuroradiology Training Charter and United States Accreditation Council for Graduate Medical Education program requirements for endovascular surgical neuroradiology [3, 4].

In East Asia, there are also governmental or nongovernmental training charters for INR in Japan, Korea and China. But there are some differences between these charters of three countries, and the courses of medical education are also different. Education and training for specialty (residency) or subspecialty (fellowship) are on the continuing education program even though the contents, format or period are different in the three countries. Therefore, different education system of the medical school also needs to be compared in each country so that the whole education and training process can be overviewed. The purpose of this paper is to describe current situation of neurointerventional activities by comparing the medical education and training of interventional neuroradiology in Japan, Korea and China.

\section{Comparison of the Undergraduate and Postgraduate Medical Education of Three Countries}

\section{Medical education in Japan}

High school graduates are eligible to enter medical school in Japan. The current standard Japanese undergraduate medical education program is six years long (Fig. 1) [5]. Typically, there are four years of preclinical education and then two years of clinical education. The initial phase of undergraduate medical education contains, to varying degrees, general education in subjects such as biology, chemistry, physics, and mathematics. There are also programs for college graduates, which are four or five years long in different schools. At the end of the final academic year, there is a graduation examination designed by each medical school. The successful examinee is awarded an M.D. degree in the graduation ceremony at the end of March. The graduates should pass the Japanese National Examination for Physicians, which is conducted once a year, before being granted a National License for Physicians and being eligible for residency training. Those who obtain a National License for Physicians may proceed to the next step, a two-year obligatory initial postgraduate clinical training program. The curriculum focuses on providing a solid grounding and effective training in primary care and general medicine, regardless of the possible future specialty choice of the physician. The advanced postgraduate clinical training programs for medical specialists are offered by the clinical departments of the medical schools and at a number of teaching hospitals. These training programs are between four or six years in length. During or after finishing this advanced

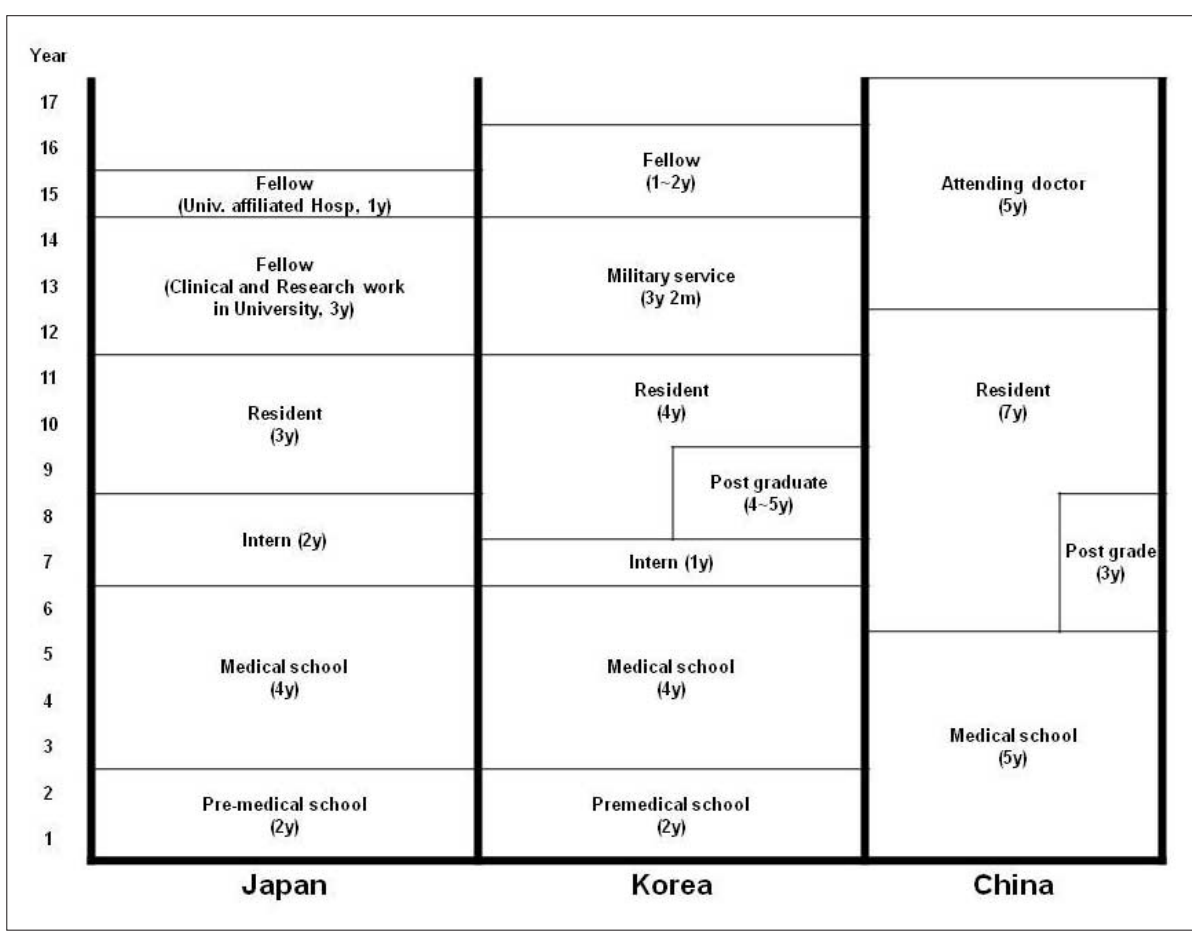

Fig. 1. Internship in Japan is a two-year obligatory initial postgraduate clinical training program. Internship in Korea will be abolished in 2015. In Korea, some of undergraduate students can enter to 4year-medical school after passing Medical Education Eligibility Test (no shown). In addition to bachelor degree $(5 y)$, there is mater (7y) or doctor (8y) degree tracts (not shown) in Chinese medical school. Attending doctor in China is almost equal to fellowship tract. 
clinical training, the trainee may sit for the board examination for a basic specialty approved by the academic societies [6].

\section{Medical education in Korea}

In Korea, it is recommended by the Ministry of Education and Human Resources that medical students should have more than six years of undergraduate education in medical schools to achieve the competence and expertise required for tomorrow's doctors (Fig. 1). This is the traditional undergraduate system with the requirement of medical school admission for applicants: high school diploma and passing National Scholastic Aptitude Test. This 6-year undergraduate program includes two years of basic medical education, two years of pre-clinical sciences and two years of clerkships. In the past years, a policy was introduced to transform four years of undergraduate education to be eligible for admission to a medical program. The requirement for applicants includes college diploma and passing Medical Education Eligibility Test. This new graduate-level professional school system require a 4-year graduate program, including one year of basic sciences, one year of preclinical sciences and two years of clerkships. As of the academic year of 2009, 34\% of the Korean medical schools have changed to the graduate school system; $35 \%$ have maintained the 6-year undergraduate system; and $31 \%$ have adopted a combined dual-mode system [7]. Graduates of medical programs go through one year of internship and three or four years of resident training, depending on specialties, followed with optional one or two years of fellowship training.

\section{Medical education in China}

Similar to Japan and Korea, most Chinese students begin their study of medicine immediately after graduation from high school, so they must spend one quarter or one third of time for the general education in such areas as mathematics, physics, foreign languages and computer technology. The typical duration for medical undergraduate education in China is five years (Fig. 1). The difference between China and the other two countries is that there are several education paths in Chinese medical schools, which are listed in Table 1 [8]. The graduated medical students must pass the National Examination for Physicians before to be a resident. The duration of residency is six years for those with bachelor degrees and three years for those with master degree after graduation. Similar with Japan, there is an obligatory initial postgraduate clinical training program which lasts two years. The training should be devoted to the general internal medicine, general surgery and emergency medicine, regardless of the possible future choice of specialty by the physician. Nowadays, "Program of the Standardized Residents Training" is commissioning in some cities, which require three years of initial resident training. There is no fellowship training in China. After the course of residency, a physician will be promoted to be an attending doctor if he or she passes the National Grade Examination. The duration of attending doctor is usually five years.

\section{The Current State Overview of INR in Japan, Korea and China}

The Japanese Society of Neuroendovascular Therapies (JSNET) was started as a small group conference in 1981 in Nagoya, and has developed to a Society which includes more than 2,500 members. JSNET contains of neurosurgeons in $90 \%$, neuroradiologists in 5\% and neurologists and others in 5\%. Board

Table 1. Educational Paths in Chinese Medical Schools

\begin{tabular}{lccll}
\hline Name of specialty & Years of study & Degree & Educational focus & Professional position \\
\hline Basic medicine & 7 or 8 & MM/MD & Experimental medicine & Research \\
\hline Clinical medicine & 7 or 8 & MM/MD & Diagnosis treatment of disease & Practice graduate medical education \\
Preventive medicine & 5 & MB & Prevention, disease, control hygiene & Public health \\
\hline Clinical medicine & 5 & MB & General medicine/clinical skills & Hospital, clinics - non-urban \\
Anesthesiology & 5 & MB & Anesthesia related subjects/skills Hospitals & Hospitals \\
\hline Radiological medicine & 5 & MB & Radiology subjects & Hospitals \\
\hline Stomatology/dentistry & 5 & MB & Diseases of mouth and teeth & Clinics hospitals \\
\hline Biological techniques & 5 & MB & Bioinformatics and biological medicine & Teaching and research \\
\hline
\end{tabular}

Abbreviations: MD, medical doctor; MM, medical master; $\mathrm{MB}$, medical bachelor. 
system started in 2000, and 142 senior (consulting) specialists and 688 specialists are now qualified.

In Korea, the situation of INR was similar to Europe. Most of neurointerventionists of the first generation are neuroradiologists, who received INR training in America or Europe and they have been practicing INR in the major hospitals in Korea. But in the last years, more and more neurosurgeons and neurologists have entered into this field. The Korean Society of Interventional Neuroradiology (KSIN) has now 196 registered members nowadays, including $147(75 \%)$ neuroradiologists, 41(22\%) neurosurgeons and 8(4\%) neuroologists.

In China, the INR was introduced in the early $1980 \mathrm{~s}$ by neurosurgeons. In the past 10 years, neurologists have become aggressive neurointerventionists with the dramatically increase of INR procedures for ischaemic diseases in the carotid and intracranial arteries in China. At the 12th Oriental Conference of Interventional Neuroradiology in October of 2012, the situation of interventional neuroradiology in China revealed that there were 1,405 registered neurointerventionists nowadays in China, of whom $833(60 \%)$ are neurosurgeons, 361(26\%) are neurologists, and $211(15 \%)$ are interventional radiologists as a least group. Comparison of the portion of neurosurgeons, neurologists and radiologists among neurointerventionists in Japan, Korea and China is shown in Figure 2.

\section{Comparison of the Specialist Training and Qualification of Interventional Neuroradiology}

In Japan, JSNET started to develop a Specialist Qualification System in 1997, and the first examination was held in 2002 [9]. Applicants for the specialist qualification are required to have more than six years of training in neurosurgery or neuroradiology after graduate medical school. This must include more than one year of training in endovascular treatment under the supervision of a consulting specialist. Applicants must have been involved in more than 100 cases of endovascular treatment with a specialist or consulting specialist as the operators, or as first or second assistant, and should have been the operators in at least 20 of these cases. The applicant is also required to have been involved in a minimum of 20 cases of aneurysm embolization, 15 cases of ischemic lesions, and five cases of arteriovenous malformation or dural arteriovenous fistula. Applicants are required to have been members of JSNET for more than four years, and have experienced over 300 cases of cerebral angiography authorized by their institute. The Specialist Qualification Examination begins with a written test, comprising 200 multiple-choice questions. Applicants also sit two 20 -minute oral tests, including caseoriented practical questions and handling test of device and material on the table. A swine model examination has been introduced for testing catheter handling since 2005. By introducing the animal model examination, the practical test was changed to an inspection. Examiner visits the examinee's institutes and inspects his procedure. Check points of the inspection include whether the strategy, skills and techniques are acceptable or not [10].

The training requirement for INR in China is contained in the "Management Standard for Diagnosis and Treatment of Interventional Neuroradiology in China", which was an official charter published by

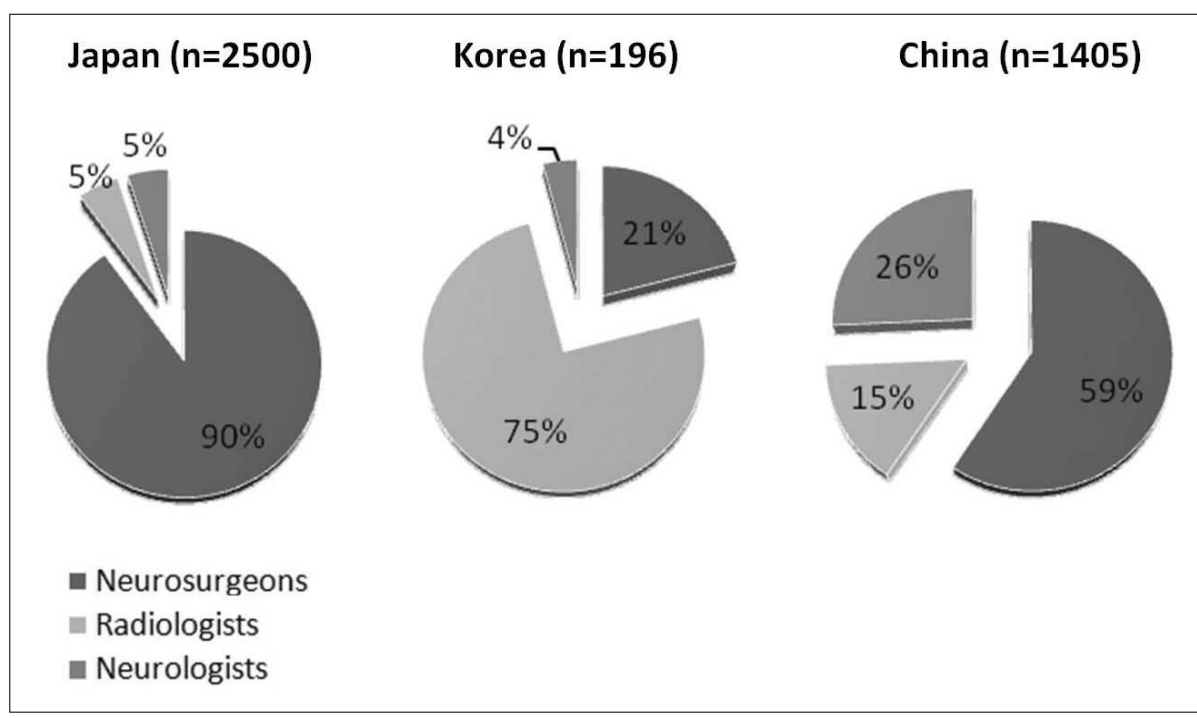

Fig. 2. Comparison of the proportion of each specialty members of neurosurgeons, neurologists and radiologists among neurointerventionists in Japan, Korea and China ( $\mathrm{n}=$ number of members). Data from Japan is from the Japanese Society of Neuroendovascular Therapies (2011). Data from China is from the 12th Oriental Conference of Interventional Neuroradiology in October of 2012. Data from Korea is from Korean Society of Interventional Neuroradiology (2011). 
INR in China, Japan and Korea

Table 2. Status and Requirement of Training Institutions in Three Countries

\begin{tabular}{|c|c|c|c|}
\hline & China & Japan & Korea \\
\hline Subspecialities (with access to INR) & INR, NS, NL & All specialities & INR, NS, NL \\
\hline Program director (subspecialty) & NS, NL, INR & NS, INR & INR, NS \\
\hline $\begin{array}{l}\text { Faculty } \\
\text { No. of members } \\
\text { Faculty / fellow ratio }\end{array}$ & $\begin{array}{l}3 \\
\text { Not specified }\end{array}$ & & Not Standardized \\
\hline $\begin{array}{l}\text { Training (duration) } \\
\text { Neurosurgery } \\
\text { Neurology } \\
\text { Neuroradiology } \\
\text { INR }\end{array}$ & $\begin{array}{l}9 \text { months } \\
9 \text { months } \\
9 \text { months } \\
1 \text { year }\end{array}$ & 1 year & Not Standardized \\
\hline $\begin{array}{l}\text { Training institutions } \\
\text { Case load } \\
\text { Equipment }\end{array}$ & $\begin{array}{l}250 / Y \\
\text { Not specified }\end{array}$ & & Not Standardized \\
\hline $\begin{array}{l}\text { Training } \\
\text { Neuroanigography } \\
\text { Endovascular procedures }\end{array}$ & $\begin{array}{l}100 / 40 \\
50 / 20\end{array}$ & $\begin{array}{l}300 \\
100 / 20\end{array}$ & Not Standardized \\
\hline $\begin{array}{l}\text { Evaluation } \\
\text { Log book } \\
\text { Final board examination }\end{array}$ & $\begin{array}{l}\text { Yes } \\
\text { Mandatory }\end{array}$ & $\begin{array}{l}\text { Yes } \\
\text { Recommended }\end{array}$ & Not Standardized \\
\hline
\end{tabular}

Abbreviations: INR, Interventional radiology; NS, Neurosurgery; NL, Neurology

Chinese Ministry of Health in 2012. In this charter, the full training to become an INR specialist is defined as two and half years of full-time training. One of these years is to be spent in core INR and nine months is to be spent in neurosurgery, neurology and neuroradiology respectively. A interventional radiologist entering this program can obtain credit for the training in radiology, so he or she only need to spend nine months in neurosurgery and neurology respectively, whereas a neurosurgeon or neurologist can similarly obtain credit for the training in neurosurgery or neurology. After finishing this training, the trainee may sit for the board examination for a certification approved by the academic societies. Qualification of applicants for the board examination includes finishing the qualified training period and the number of procedures at the designated teaching facility required by the charter. Applicants must have experienced over 100 cases of cerebral or spinal angiography authorized by their institute, and been involved in more than 50 cases of endovascular treatment with a specialist as the operators, or as first or second assistant, and should have been the operators in at least 20 of these cases. As to those applicants accepting training abroad, they must have finished one year of core INR training and the number of procedures, and get the certification of the teaching facility. The qualification examination includes written test and practical test carried by academic society, but there is still no uniform introduction published for this examination. Successful applicants are given the title of board-certified INR specialist of the academic society. Status and requirement of training institutions in three countries are shown in Table 2.

In Korea, there is neither standardized fellowship program nor final subspecialty board examination. Most of the faculties in the university hospital spend one or two years as a visiting doctor or fellow in the United State or European countries during their sabbatical year. There is also visiting doctor program in China and Japan. Recently some of them spend their sabbatical year in Asian countries. There are two Societies in Korea: the Korean Society of Interventional Neuroradiology (KSIN) belongs to the Korean Radiological Society but is almost independent. KSIN has open policy to other specialty for other subspecialty members. Recently established the Society of Korean Endovascular Neurosurgeons (SKEN) belongs to the Korean Neurosurgical Society (KNS) and the Korean Society of Cerebrovascular surgeons (KSCS, subdivision of KNS). SKEN has closed policy to other specialty. The official journal of SKEN recently 
merged to J Cerebrovasc Endovasc Neurosurg which has been official journal of KSCS.

In summary, medical education or INR training program of three countries differs in presence of premedical school (Japan and Korea), long military service (Korea), internship (Japan and Korea) or long residency period (China). Qualification of subspecialty which is present in Japan and is recently established in China is one issue in INR field in which trainees come from different specialties with different training background. Comparison of medical education and INR training systems among different countries may be beneficial to make an emerging new field such as INR develop further.

\section{References}

1. Flodmark O, Grisold W, Richling B, Mudra H, Demuth R, Pierot L. Training of future interventional neuroradiologists: the European approach. Stroke 2012;43:2810-2813

2. Picard L, Negoro M, Ter Brugge K, Mawad M, Lasjaunias P, Vinuela F, et al. 1998 world Federation of interventional and therapeutic neuroradiology. Guidelines for fellowship training programmes in interventional neuroradiology. Interv Neuroradiol 1998;4:195-197
3. European Union for Medical Specialists. UEMS recommandations for acquiring "Particular Qualification" in endovascular interventional neuroradiology-INR. EJMINT 2012:1212000052

4. Accreditation Council for Graduate Medical Education. ACGME Program Requirements for Graduate Medical Education in Endovascular Surgical Neuroradiology. ACGME Approved Focused Revision: September 30, 2012; Effective: July 1, 2013.

5. Spiotta AM, Sivapatham T, Hussain MS, Moskowitz SI, Rasmussen PA, Masaryk TJ, et al. Benefits of a multidisciplinary environment for neurointerventional training: fellows' perspectives. J Neurointerv Surg 2012;4:238-240

6. Kozu T. Medical education in Japan. Acad Med 2006;81:10691075

7. Kim KJ, Kee C. Reform of medical education in Korea. Med Teach 2010;32:113-117

8. Ren X, Yin J, Wang B, Roy Schwarz M. A descriptive analysis of medical education in China. Med Teach 2008;30:667-672

9. Taki W, Gotoh K, Hyodo A, Hyogo T, Kinugasa K, Koike T, et al. Editorial: the first specialist qualification examination of the Japanese Society of Intravascular Neurosurgery (JSIN). Interv Neuroradiol 2002;8:343-345

10. Hyogo T, Taki W, Negoro M, Takahashi A, Edura M, Hyodo A, et al. Japanese society of neuro-endovascular treatment specialist qualification system. Six years' experience and introduction of an animal model examination. Interv Neuroradiol 2008;14:235-240 